\title{
Effect of Ficus sycomorus L. Leaves on High Fat Diet-Fed Rats: Possible Mechanisms behind the Prevention of Obesity and Its Related Disorders
}

\author{
Samah A. El-Hashash, $\mathrm{PhD}$ \\ Nutrition and Food Science Dept., Faculty of Home Economics, Al-Azhar University, Egypt.
}

\begin{abstract}
The main target of this study was to investigate the protective effect of Ficus sycomorus L. leaves (FSLs) against high fat diet (HFD)-induced obesity and the possible mechanisms behind this effect in experimental rats. 30 male albino rats (Sprague Dawley strain) weighing $98.61 \pm 5.87 \mathrm{~g}$ were used and randomly divided into five equal groups including the control besides HFD, HFD + 2.5\% FSLs, HFD + 5\% FSLs and HFD + 7.5\% FSLs- fed groups. High fat diet was prepared using $20 \%$ fat $(19 \%$ sheep tallow $+1 \%$ soybean oil), while basal diet contained 4\% soybean oil. The experiment lasted for 6 weeks. Feed intake, body weight gain and liver weight/ body weight (\%) were finally calculated. Leptin, pancreatic lipase, glucose, lipid profiles, liver enzymes, urea and creatinine were also determined in serum. Moreover, livers of sacrificed rats were histopathologically examined. Results indicated that feeding on high fat diet resulted in a significant increase in body weight, relative liver weight and the serum concentrations of leptin, pancreatic lipase, glucose, triglycerides, total cholesterol, $L D L-C, V L D L-C$, transaminases, alkaline phosphatase, urea and creatinine, while daily feed intake and serum HDL-C were significantly declined. Addition of dried FSLs to high fat diet led to a significant decrease in body weight gain, relative liver weight and the serum levels of leptin and pancreatic lipase. They also showed hypoglycemic and hypolipidemic effects, improved liver and kidney functions and reversed the marked lesion noticed in liver tissue. In general, the more the dose used, the better the effect noticed. Accordingly, it was concluded that Ficus sycomorus L. leaves could hinder weight gain and prevent its related disorders. So, dietary supplementation with Ficus sycomorus L. leaves should be implicated in the antiobesity strategies.
\end{abstract}

Keywords: Ficus sycomorus L. leaves, Functional foods, High fat diet, obesity, rats.

\section{Introduction}

Obesity is one of the greatest threats to global health in this century, with more than 1.5 billion overweight adults and at least 400 million of clinically obese subjects [1]. Due to these increasing obesity rates, the World Health Organization (WHO) has prompted to consider it as the epidemic of XXI century and to promote strategies to prevent and control its complications [2]. About 35\% of Egyptian adults (18.7\% males \& $48.1 \%$ females) are considered to be obese [3].

Obesity is a multifactorial disease characterized by an excessive weight for height as a result of an enlarged fat deposition such as adipose tissue, which is attributed to a higher calorie intake than the energy expenditure [4]. Being obese can induce multiple metabolic disorders that contribute to cardiovascular disease, diabetes mellitus and other chronic diseases [5].

The key strategy to overcome obesity is to prevent chronic positive impairments in the energy equation. However, it is often difficult to maintain energy balance, because many available foods are high-energy yielding, which is usually accompanied by a decreased physical activity. The pharmaceutical industry has invested major efforts in producing antiobesity drugs. Nowadays trend, however, is to identify and screen new natural products that are more potent or have less secondary effects than these drugs [4].

Ficus sycomorus Linn belongs to the family Moraceae, comprising about 40 genera and over 1,400 species of trees, shrubs, vine and herbs, often with milky latex juices. They are usually found near streams in Palestine and many African countries. F. sycomorus is a tree that grows up to $20 \mathrm{~m}$ with widely spreading branches and a massive crown. Sheep and cattle eat its foliage [6-8]. Ficus sycomorus is used in Nigeria, Niger, Mali, South Africa, Guinea, Kenya, Tanzania, Somalia, Ethiopia and Ivory Coast as extracts of fruits, leaves, root and stem barks to treat various ailments such as cough, diarrhea, skin infections, stomach disorders, liver disease, epilepsy, tuberculosis, lactation disorders, helminthiasis, infertility, sterility and diabetes mellitus $[9,8]$. The plant has also been reported to be a potent antimicrobial agent against ciprofloxacin resistant Salmonella typhi [10]. In Palestine, the milky sap from $F$. sycomorus stem bark is used for treating skin diseases while a decoction of the stem bark is used for problems of the gastrointestinal tract. It is also used as seasoning, leaves are dried and added to cake as a condiment, eaten raw or cooked as soup. Dry branches of the species are collected for use as fuel [11]. 
Leaves of Ficus sycomorus Linn are heart-shaped with a round apex, $14 \mathrm{~cm}$ long by $10 \mathrm{~cm}$ wide. The flowering and fruiting usually occurs from July to December. The proximate composition of dry F. sycomorus leaves was determined by [12] and it was found that they have high contents of both protein and crude fibers, while ash, lipid and carbohydrate contents were within the range expected for dry leafy vegetables [13]. Ficus sycomorus $\mathrm{L}$. leaves afforded also psoralene ( 0.9 per cent yield) and the unsaponiflable fraction of the fat was found to contain $\beta$-amyrin lupeol and $\beta$-sitosterol [14].

Although availability, inexpensiveness and high nutritional value, Ficus sycomorus L. "Gemmayz" leaves are not commonly consumed in Egypt either as a dietary source or as a therapeutic agent. As one of the many studies needed to exhibit the health and nutritional benefits of this non-conventional source, this study was carried out to examine the protective effect of $F$. sycomorus L. leaves (FSLs) against obesity and its related disorders in experimental rats.

\section{Materials and Methods}

\subsection{Materials:}

\subsubsection{Plant material:}

Ficus sycomorus $\mathrm{L}$. leaves were sampled from different parts of Nawag village, Tanta City, Al-Gharbia Governorate, Egypt.

\subsubsection{Animals:}

A total of 30 normal male albino rats (Sprague_ Dawley strain) weighing $90 \pm 5 \mathrm{~g}$ were obtained from the animal colony, Helwan Farm, Vaccine and Immunity Organization, Cairo, Egypt.

\subsubsection{Chemicals and other required materials:}

Casein, vitamins, minerals, cellulose, choline chloride and DL-methionine were obtained from Elgomhoreya Company for Chemicals and Drugs, Cairo, Egypt. Sheep tallow, sucrose, soybean oil and corn starch were obtained from the local market, Tanta City, Al-Gharbia Governorate, Egypt.

\subsection{Methods:}

\subsubsection{Preparation of plant material:}

Ficus sycomorus L. leaves were sampled in October, 2012 and dried at room temperature away from sunlight. They were then milled to a fine powder-using pestle and motor (stainless steel) and stored at room temperature in closed glass bottles in the dark until used.

\subsubsection{Study design \& Blood sampling:}

Male albino rats $(\mathrm{n}=30)$ of Sprague Dawley strain weighing $(90 \pm 5 \mathrm{~g})$ were housed in well-aerated cages under hygienic conditions " $22-25^{\circ} \mathrm{C}$ and a $12 \mathrm{~h}$ light-dark cycle" and fed basal diet for one week for adaptation. After this period, rats were divided into five equal groups. The first group was fed basal diet as a control group. Other groups were fed high fat diet (HFD) alone or HFD plus $2.5 \%, 5 \%$ or $7.5 \%$ of dried Ficus sycomorus L. leaves (FSLs). Basal diet used was formulated according to Reeves et al. [15], while HFD was formulated according to Woods et al., [16] with some modifications "Table 1". The experiment continued for six weeks. Meanwhile, diet and water were provided ad-libitum and feed intake was calculated and recorded once a week.

Table 1: Composition of basal and high fat diets used in the experiment (g/kg diet)

\begin{tabular}{|l|c|c|}
\hline \multicolumn{1}{|c|}{ Ingredient } & Basal diet & HFD \\
\hline Casein ( $\geq 85 \%$ protein) & 140 & 164 \\
Soybean oil & 40 & 10 \\
Sheep tallow & - & 58.6 \\
Cellulose & 50 & 11.7 \\
Vitamin mixture & 10 & 41 \\
Mineral mixture & 35 & 2.9 \\
Choline chloride & 2.5 & 2.1 \\
L- Cystine & 1.8 & 0.009 \\
Tert-butylhydroquinone & 0.008 & 89.9 \\
Sucrose & 100 & 115 \\
Dextrinized corn starch & 155 & 314.79 \\
Corn starch & 465.69 & \\
\hline
\end{tabular}

At the end, animals were fasted overnight before sacrificing. Blood samples were collected from the aorta of each rat into dry centrifuge tubes. Sera were carefully separated by centrifugation of blood samples at $3000 \mathrm{rpm}$ (round per minute) for 10 minutes at room temperature, then transferred into dry clean ebendorf tubes 
and serum glucose was immediately determined. Afterwards, sera were kept frozen at $-20^{\circ} \mathrm{C}$ for other latter determinations. Livers also were removed by careful dissection, washed in saline solution $(0.9 \%)$, dried using filter paper and weighed.

\subsubsection{Feed intake, body weight gain and relative organ's weight calculation:}

At the end of the experiment, total feed intake (FI) was calculated by subtracting the remainder food for each animal from that allocated to it. In the same time, food wastage was weighed and subtracted. Daily feed intake was calculated through division of total feed intake by 41. Body weight gain (BWG) was also calculated by subtracting the initial weight of each rat from its final weight. As for relative liver weight, it was calculated according to Angervall and Carlström, [17].

\subsubsection{Biochemical analysis:}

Sera were analyzed for the determination of leptin [18], pancreatic lipase (PL) [19] and glucose [20]. Lipid profiles were also determined including triglycerides (TG) [21], total cholesterol (TC) [22], high, low and very low-density lipoprotein-cholesterol (HDL-C, LDL-C and VLDL-C) [23]. In addition, liver functions were determined including aminotransferases' (AST and ALT) activities [24] and alkaline phosphatase (ALP) activity [25]. Moreover, kidney functions were determined including urea [26] and creatinine [27].

\subsubsection{Histopathological examination:}

Livers of sacrificed rats were taken and immersed in $10 \%$ buffered neutral formalin solution. The fixed specimens were then trimmed, washed and dehydrated in ascending grades of alcohol. They were then cleared in xylol, embedded in paraffin, cut in sections of 4-6 microns thickness and stained with haematoxylin and cosin according to Drury and Wallington, [28].

\subsubsection{Statistical analysis:}

Statistical analysis was carried out using the programme of statistical package for the social sciences (SPSS), PC statistical soft ware (Version 20; Untitled - SPSS Data Editor). The results were expressed as mean \pm standard deviation (mean $\pm \mathrm{SD}$ ). Data were analyzed using one-way classification, analysis of variance (ANOVA) test. The differences between means were tested for significance using Duncan test at $\mathrm{p}<0.05$ [29].

\section{Results}

Effects of high fat diet supplemented with different doses of Ficus sycomorus leaves (FSLs) on feed intake (FI), body weight gain (BWG), relative liver weight, as well as the concentrations of leptin and pancreatic lipase (PL) in sera of experimental rats were illustrated in "Table 2".

It could be noticed that unsupplemented high fat diet-fed group recorded a significant decrease in the daily feed intake compared with the control group fed on basal diet. Supplementation of high fat diet with FSLs in all their doses resulted in a significant increase as compared to high fat diet only, while there were no significant differences compared with the control. On the other hand, there were no significant differences among FSLs-treated groups.

There were no significant differences among all experimental groups in their initial weights. By the end of the experiment, the weight of HFD-fed group was significantly increased compared with the control group fed on basal diet. Supplementation of HFD with FSLs (2.5\%) induced no significant change in the final weight compared with HFD-fed group, while the higher doses of FSLs (5 and 7.5\%) led to a significant decrease. Regarding BWG, HFD-fed group recorded a significant increase compared with the control group and all doses of FSLs induced significant decreases compared with HFD-fed group. In the same time, neither the final weights nor the mean values of BWG in the FSLs-treated groups returned toward their normal values recorded by the control group.

Relative liver weight did not significantly increase in HFD-fed group as compared to the control group. All doses of FSLs led to no significant change compared with HFD-fed group. On the other hand, they induced no significant increase compared with the control group, except for the medium dose (5\%) as it caused a significant elevation.

The mean value of serum leptin was significantly increased in HFD-fed group as compared to the control one. Only the group treated with the low dose of FSLs recorded no significant difference compared with HFD-fed group, while other doses (5 and 7.5\%) caused significant decreases and the high dose was so efficient that could return this parameter toward its normal value noticed in the control group.

As for pancreatic lipase (PL), it was noticed that HFD-fed group recorded a significant increase as compared to the control group. All doses of FSLs induced significant decreases compared with HFD-fed group. In the same time, they could not return it toward its normal value recorded by the control group.

Generally, it could be observed that the more the dose of FSLs used, the better the results obtained. 
Table 2: Effects of high fat diet supplemented with different doses of Ficus sycomorus leaves (FSLs) on feed intake (FI), body weight gain (BWG), relative liver weight, as well as the concentrations of leptin and pancreatic lipase (PL) in sera of experimental rats

\begin{tabular}{|c|c|c|c|c|c|}
\hline $\begin{array}{l}\text { Groups } \\
\text { Parameters }\end{array}$ & Control & HFD & $\begin{array}{c}\text { HFD+FSLs } \\
(2.5 \%) \\
\end{array}$ & $\begin{array}{c}\text { HFD+FSLs } \\
(5 \%)\end{array}$ & $\begin{array}{c}\text { HFD+FSLs } \\
(7.5 \%)\end{array}$ \\
\hline Initial weight (g) & $99.25 \pm 4.26^{\mathrm{a}}$ & $98.00 \pm 7.01^{\mathrm{a}}$ & $100.80 \pm 6.70^{\mathrm{a}}$ & $97.33 \pm 8.73^{\mathrm{a}}$ & $97.67 \pm 1.21^{\mathrm{a}}$ \\
\hline BWG (g) & $13.11 \pm 1.11^{\mathrm{a}}$ & $66.92 \pm 0.76^{\mathrm{d}}$ & $59.47 \pm 0.55^{\mathrm{c}}$ & $59.10 \pm 4.35^{\mathrm{c}}$ & $50.94 \pm 2.10^{b}$ \\
\hline Liver weight (\%) & $2.66 \pm 0.11^{\mathrm{a}}$ & $2.74 \pm 0.11^{\mathrm{ab}}$ & $2.78 \pm 0.09^{\mathrm{ab}}$ & $2.78 \pm 0.10^{b}$ & $2.69 \pm 0.04^{\mathrm{ab}}$ \\
\hline Leptin (ng/mL) & $6.04 \pm 0.24^{\mathrm{a}}$ & $6.85 \pm 0.12^{c}$ & $6.84 \pm 0.10^{c}$ & $6.45 \pm 0.15^{b}$ & $6.16 \pm 0.07^{\mathrm{a}}$ \\
\hline
\end{tabular}

- Values that have different letters in each row differ significantly, while the difference among those with similar letters completely or partially is not significant.

Effects of high fat diet supplemented with different doses of Ficus sycomorus leaves (FSLs) on glucose and lipid profiles in sera of experimental rats were illustrated in "Table 3 ".

It could be noticed that unsupplemented high fat diet-fed group recorded a significant increase in the mean values of glucose, TG, TC, LDL-C and VLDL-C in sera compared with the control group fed on basal diet. In contrast, serum HDL-C was significantly reduced.

Supplementation of high fat diet with FSLs in all their doses resulted in a significant decrease in the mean values of serum glucose, TG, TC, LDL-C and VLDL-C as compared to high fat diet only. When compared with the control group, groups treated with either $2.5 \%$ or 5\% FSLs recorded no significant differences in the mean values of serum glucose, TG and VLDL-C, while the group treated with $7.5 \%$ FSLs recorded a significant decrease. While all FSLs-treated groups recorded no significant decreases in serum total cholesterol compared with the control group, they recorded significant increases in serum LDL-C.

Serum HDL-C did not significantly differ in all FSLs-treated groups compared with high fat diet-fed group and only the group treated with 7.5\% FSLs recorded no significant decrease as compared to the control group.

Table 3: Effects of high fat diet supplemented with different doses of Ficus sycomorus leaves (FSLs) on glucose and lipid profiles in sera of experimental rats

\begin{tabular}{|l|c|c|c|c|c|}
\hline \multicolumn{1}{|c|}{ Groups } & Control & HFD & $\begin{array}{c}\text { HFD+FSLs } \\
\mathbf{( 2 . 5} \%)\end{array}$ & $\begin{array}{c}\text { HFD+FSLs } \\
\mathbf{( 5 \% )}\end{array}$ & $\begin{array}{c}\text { HFD+FSLs } \\
\mathbf{( 7 . 5} \%)\end{array}$ \\
\hline Parameters & $102.0 \pm 9.49^{\mathrm{b}}$ & $125.0 \pm 9.94^{\mathrm{c}}$ & $107.4 \pm 11.0^{\mathrm{b}}$ & $105.50 \pm 9.89^{\mathrm{b}}$ & $79.50 \pm 3.61^{\mathrm{a}}$ \\
\hline Glucose (mg/dl) & $85.67 \pm 6.94^{\mathrm{b}}$ & $102.5 \pm 7.06^{\mathrm{c}}$ & $79.83 \pm 6.68^{\mathrm{ab}}$ & $79.00 \pm 5.66^{\mathrm{ab}}$ & $76.40 \pm 3.77^{\mathrm{a}}$ \\
\hline TG (mg/dl) & $85.00 \pm 5.02^{\mathrm{a}}$ & $93.50 \pm 2.26^{\mathrm{b}}$ & $84.83 \pm 6.41^{\mathrm{a}}$ & $83.80 \pm 2.93^{\mathrm{a}}$ & $82.00 \pm 5.02^{\mathrm{a}}$ \\
\hline HDL-C (mg/d) & $56.00 \pm 2.28^{\mathrm{b}}$ & $47.67 \pm 3.37^{\mathrm{a}}$ & $48.40 \pm 4.63^{\mathrm{a}}$ & $49.00 \pm 5.51^{\mathrm{a}}$ & $51.40 \pm 3.71^{\mathrm{ab}}$ \\
\hline LDL-C (mg/dl) & $11.87 \pm 0.80^{\mathrm{a}}$ & $25.33 \pm 2.06^{\mathrm{d}}$ & $20.47 \pm 1.38^{\mathrm{c}}$ & $19.00 \pm 1.30^{\mathrm{c}}$ & $15.32 \pm 1.25^{\mathrm{b}}$ \\
\hline VLDL-C (mg/dl) & $17.13 \pm 1.39^{\mathrm{b}}$ & $20.50 \pm 1.41^{\mathrm{c}}$ & $15.97 \pm 1.34^{\mathrm{ab}}$ & $15.80 \pm 1.13^{\mathrm{ab}}$ & $15.28 \pm 0.75^{\mathrm{a}}$ \\
\hline
\end{tabular}

- Values that have different letters in each row differ significantly, while the difference among those with similar letters completely or partially is not significant.

Effects of high fat diet supplemented with different doses of Ficus sycomorus leaves (FSLs) on liver and kidney functions in experimental rats were illustrated in "Table 4".

It could be noticed that feeding on unsupplemented high fat diet resulted in a significant increase in the activities of liver enzymes (AST, ALT and ALP), as well as the concentrations of urea and creatinine in sera compared with the control group fed on basal diet.

Supplementation of high fat diet with FSLs in all used doses caused a significant decrease in creatinine concentration and the activities of AST, ALT and ALP in sera compared with high fat diet only. When compared with the control group, groups treated with 5\% or 7.5\% FSLs recorded significant decreases in AST activity in serum, while the group treated with $2.5 \%$ FSLs recorded no significant decrease. While all FSLstreated groups recorded no significant changes in the activities of both ALT and ALP in sera compared with the control group, they recorded significant decreases in serum creatinine.

Serum urea was not significantly affected in the groups fed on high fat diet supplemented with either $2.5 \%$ or $5 \%$ FSLs compared with the group fed on HFD only, while supplementation with $7.5 \%$ FSLs was so efficient that not only significantly reduced serum urea compared with HFD-fed group, but also returned it toward its normal value recorded by the control group.

Generally, it could be observed that the more the dose of FSLs used, the more the decrease in enzyme activities and protein metabolites recorded. 
Table 4: Effects of high fat diet supplemented with different doses of Ficus sycomorus leaves (FSLs) on liver and kidney functions in experimental rats

\begin{tabular}{|c|c|c|c|c|c|}
\hline $\begin{array}{l}\text { Groups } \\
\text { Parameters }\end{array}$ & Control & HFD & $\begin{array}{c}\text { HFD+FSLs } \\
(2.5 \%)\end{array}$ & $\begin{array}{c}\text { HFD+FSLs } \\
(5 \%)\end{array}$ & $\begin{array}{c}\text { HFD+FSLs } \\
(7.5 \%)\end{array}$ \\
\hline AST (U/L) & $95.33 \pm 5.85^{c}$ & $104.83 \pm 7.24^{d}$ & $88.83 \pm 3.47^{\mathrm{c}}$ & $77.20 \pm 7.98^{b}$ & $68.60 \pm 6.77^{\mathrm{a}}$ \\
\hline $\operatorname{ALT}(\mathrm{U} / \mathrm{L})$ & $20.67 \pm 0.37^{\mathrm{a}}$ & $24.75 \pm 1.60^{b}$ & $20.80 \pm 2.48^{\mathrm{a}}$ & $20.25 \pm 1.72^{\mathrm{a}}$ & $20.25 \pm 1.16^{\mathrm{a}}$ \\
\hline ALP (U/L) & $186.07 \pm 3.17^{\mathrm{ab}}$ & $214.50 \pm 9.60^{c}$ & $196.83 \pm 8.47^{b}$ & $188.42 \pm 16.77^{\mathrm{ab}}$ & $177.50 \pm 9.13^{\mathrm{a}}$ \\
\hline Urea (mg/dl) & $30.20 \pm 2.87^{\mathrm{a}}$ & $35.50 \pm 2.41^{b}$ & $35.33 \pm 2.85^{b}$ & $34.25 \pm 0.67^{b}$ & $29.40 \pm 2.42^{\mathrm{a}}$ \\
\hline Creatinine (mg/dl) & $0.57 \pm 0.05^{b}$ & $0.66 \pm 0.02^{\mathrm{c}}$ & $0.52 \pm 0.04^{\mathrm{a}}$ & $0.51 \pm 0.04^{\mathrm{a}}$ & $0.50 \pm 0.02^{\mathrm{a}}$ \\
\hline
\end{tabular}

- Values which have different letters in each row differ significantly, while the difference among those with similar letters completely or partially is not significant.

Results of the histopathological examination of rat livers from different experimental groups were illustrated in Figs. (1-6):-

Fig. (1) represents liver of rat from control group, in which the normal histological structure of hepatic lobule can be observed. Feeding HFD led to marked lesions in liver tissue including congestion of portal vein, proliferation of bile ductules and fibroplasia in portal triad associated with portal infiltration with inflammatory cells (Fig. 2), vaculation of cytoplasm, kupffer cells activation and fatty degeneration of hepatocytes (Fig. 3). Addition of FSLs to HFD somewhat decreased these lesions. For example, Fig. (4) represents liver of rat from the group fed HFD+2.5\% FSLs, in which kupffer cell activation, karyolysis of many nuclei, elongation and congestion of blood vessel can be noticed. In Fig. (5), liver of rat from the group fed HFD+5\% FSLs was represented, in which congestion and disruption of blood vessels and dilatation of sinusoids can be observed. Increasing the dose of FSLs to $7.5 \%$ resulted in obvious improvement in liver tissue as normal like architecture of hepatocytes around the central vein was found, Fig. (6). As noticed, the more the dose of FSLs used, the more the improvement in liver tissue recorded.

\section{Discussion}

Feeding high fat diet, in the present study, led to a significant increase in BWG and serum leptin. These findings are in harmony with Woods et al., who demonstrated that high fat diet-fed rats weighed more than low fat controls and defended this weight in the face of changes in energy availability. Additionally, they developed substantially more adipose tissue than controls and acquired the insulin insensitivity and hyperleptinemia typically associated with obesity [16]. It was also suggested that fat accumulation is greater when more energy comes from dietary fat than from carbohydrate or protein [30,31]. Loss of leptin, an adipocyte-derived hormone, or leptin receptor expression, in both humans and animal models [32,33], leads to a striking elevation in feed intake. Thus, the decreased feed intake of the HFD-fed group, in the present study, can be attributed to the elevated concentration of serum leptin. However, this elevated leptin concentration failed to return body adiposity to the normal range reflecting a somewhat resistance to hormone action.

The elevating effect of HFD on relative liver weight, as noticed in the present study, is in consistence with Zivkovic et al., who explained that excessive or inappropriate dietary fat intake combined with peripheral insulin resistance, continued insulin-stimulated triglyceride hydrolysis via lipoprotein lipase (LpL), and many other possible genetic alterations in key lipid metabolic pathways tend to result in increased blood free fatty acid concentrations. This leads to excessive skeletal muscle fat accumulation and increased liver concentrations of TG and cholesterol esters [34].

In accordance with the present result regarding the effect of HFD on the level of pancreatic lipase in serum, Gidez has demonstrated that levels of pancreatic lipase are increased when the fat content of the diet is raised from about $5 \%$ to $15-22 \%$ [35].

Dietary fibers exert inhibitory actions on pancreatic lipase [36,37]. Thus, the high content of crude fibers in dry $F$. sycomorus leaves $(31.54 \pm 0.11 / 100 \mathrm{~g})$ [12] can account the reduced effect of FSLs supplemented HFD diet compared with HFD alone on serum pancreatic lipase. On the other hand, acetone extract of dried $F$. sycomorus leaves was found to be a weak and a potent inhibitor of $\alpha$-glucosidase (sucrase) and $\alpha$-amylase activities, respectively [38]. Indigestion of fats and carbohydrates, the basic energy providers, is a logic cause for the decreasing effect of FSLs -supplemented HFD diet on body weight. The total polyphenol content of dried $F$. sycomorus leaves (12.33 $\pm 0.26 \mathrm{mg}$ gallic acid equivalent $/ \mathrm{g}$ ) [38] may also add another cause for such effect since polyphenols can prevent obesity via several mechanisms including suppression of fat absorption from the gut, uptake of glucose by skeletal muscles, suppression of anabolic pathways, stimulation of catabolic pathways in adipose, liver and other tissues, inhibition of angiogenesis in adipose tissues, inhibition of differentiation of pre-adipocytes to adipocytes and stimulation of apoptosis of mature adipocytes [39]. Because circulating leptin concentrations are commensurate with overall adipose mass [40] and there is a significant inverse association between dietary fibers and serum leptin concentration [41,42], FSLs -supplemented HFD diet, in the present study, had a lowering effect on serum leptin compared with HFD alone. This effect, in turn, 
resulted in a significant increase in daily feed intake. Through enhancing insulin sensitivity and decreasing fat digestion and/or absorption, fibers [43, 36, 37], and polyphenols [39] in $F$. sycomorus leaves may exert inhibitory actions on fat accumulation in liver tissues leading to a marked decrease in relative liver weight.

Serum glucose of HFD-fed group, in our study, was significantly higher compared with the control group. The mechanisms by which HFD induces hyperglycemia include increased amylase secretion [44], insulin resistance and islet dysfunction [45]. Through inhibiting of pancreatic enzymes responsible for carbohydrate digestion [38], inducing weight loss and alleviating insulin resistance, FSLs -supplemented HFD diet, in the present study, had a hypoglycemic effect compared with HFD alone.

Besides increasing pancreatic lipase levels, high fat diet has an indirect dyslipidemic action. High fat diet increases the fat mass in the body, which, in turn, is associated with low circulating adiponectin concentrations [46]. Adiponectin, a 30-kDa protein, is an anti-inflammatory, anti-atherogenic and insulinsensitizing hormone [47]. It is thought that in the insulin-resistant state, due to low adiponectin levels and/or other causes, triglyceride-rich lipoproteins accumulate in the circulation due to decreased activity of lipoprotein lipase [48], increased lipolysis in adipose tissue [49] and increased output of VLDL particles from the liver [50]. Progressive elimination of lipid and apolipoproteins from the VLDL particle results in an increased formation of intermediate-density and low-density lipoproteins, both of which are atherogenic [51]. Moreover, the delay in plasma lipoprotein triglyceride clearance allows for cholesterol esters to be passed on from HDL to triglyceriderich particles, which leads to potentially atherogenic lipoproteins particles [52]. Via decreasing pancreatic lipase level and /or activity and improving insulin sensitivity, FSLs -supplemented HFD diet, in the present study, exerted a hypolipidemic effect.

High-fat diets have been shown to produce fatty liver in both animal [53] and human [54] studies through various mechanisms. Of them, insulin resistance and oxidative stress are the most important [55]. Undoubtedly, a disturbance of liver functions is the result of this injury including the increased production and excretion of liver enzymes. FSLs are rich in crude fibers [12] and possess antioxidant activity [56,38]. This, in turn, accounts for the lowering effect of FSLs on the three studied liver enzymes.

Mice on a HFD developed increased urinary albumin excretion and glomerular lesions with the accumulation of extracellular matrix protein. Moreover, renal pathophysiological alterations, including lipid accumulation, macrophage infiltration, increased oxidative stress and impaired sodium handling were also noticed [57]. On the other hand, it was found that insulin resistance correlated linearly with decline in renal function [58]. Thus, these studies support the present findings and explain the mechanisms by which HFD induces renal dysfunction. Accordingly, FSLs are expected to improve kidney functions via combating oxidative stress and insulin insensitivity.

Almost all the beneficial effects of FSLs were attributed to their fiber and antioxidant contents. Undoubtedly, the more the dose used, the higher the content of fiber and antioxidants in the obtained diet, hence the better the effect noticed.

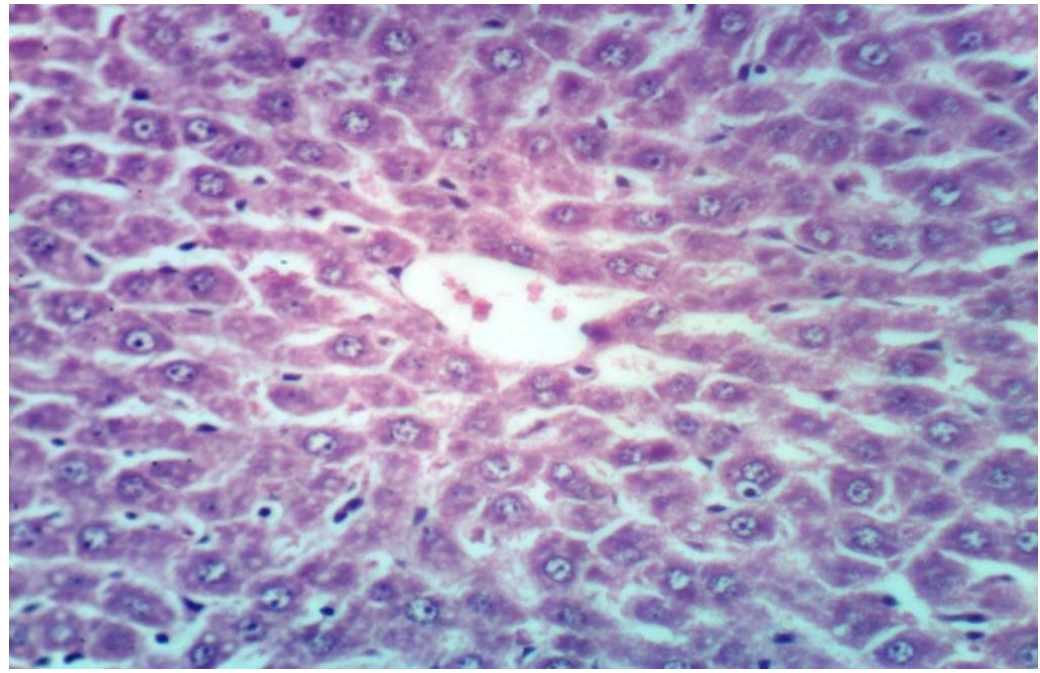

Fig. 1. Representative hematoxylin and eosin staining of the rat liver tissues of control group shows normal histological structures of hepatic lobule $(\mathrm{H}$ and $\mathrm{E} \times 400)$. 


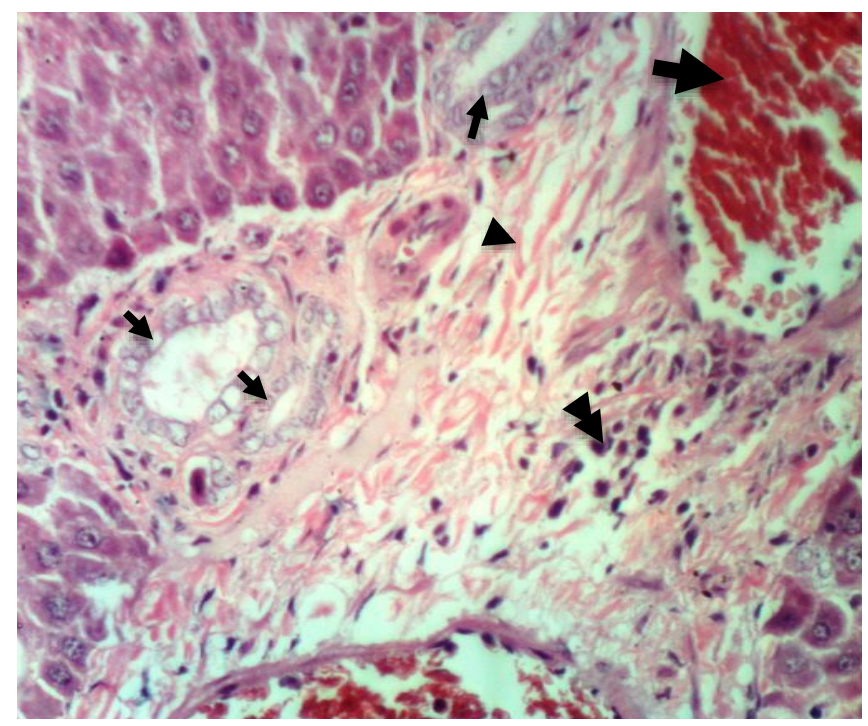

Fig. 2. Representative hematoxylin and eosin staining of the rat liver tissues of HFD -fed group shows congestion of portal vein (thick arrow), and proliferation of bile ductules (thin arrows), as well as fibroplasia in portal triad (arrowhead) that was associated with a portal infiltration with inflammatory cells (double arrowhead , $\mathrm{H}$ and $\mathrm{E} \times 400)$.

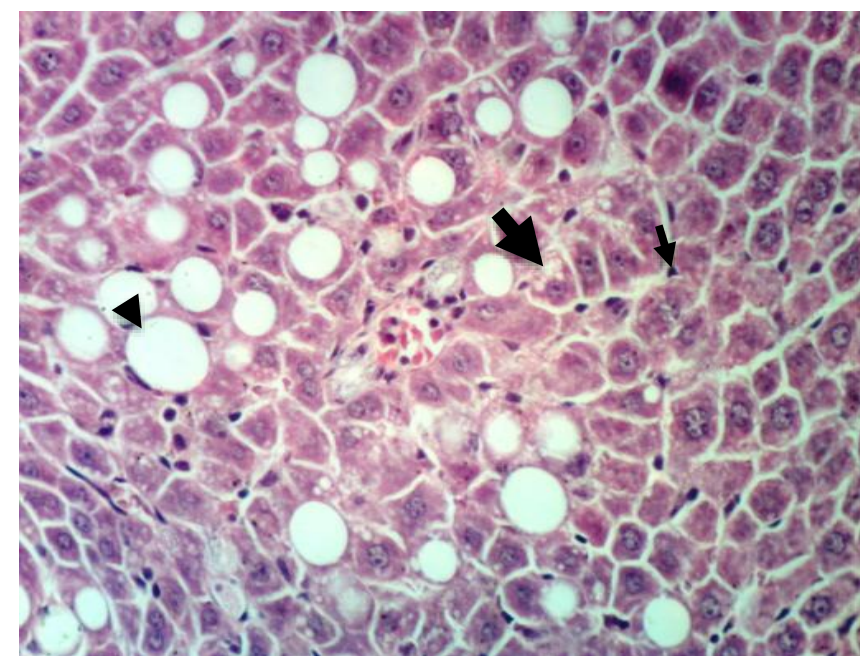

Fig. 3. Representative hematoxylin and eosin staining of liver tissues of another rat from HFD -fed group shows vaculation of cytoplasm (thick arrow), and kupffer cells activation (thin arrows) as well as fatty degeneration of hepatocytes (arrowhead $\mathrm{H}$ and $\mathrm{E} \times 400$ ).

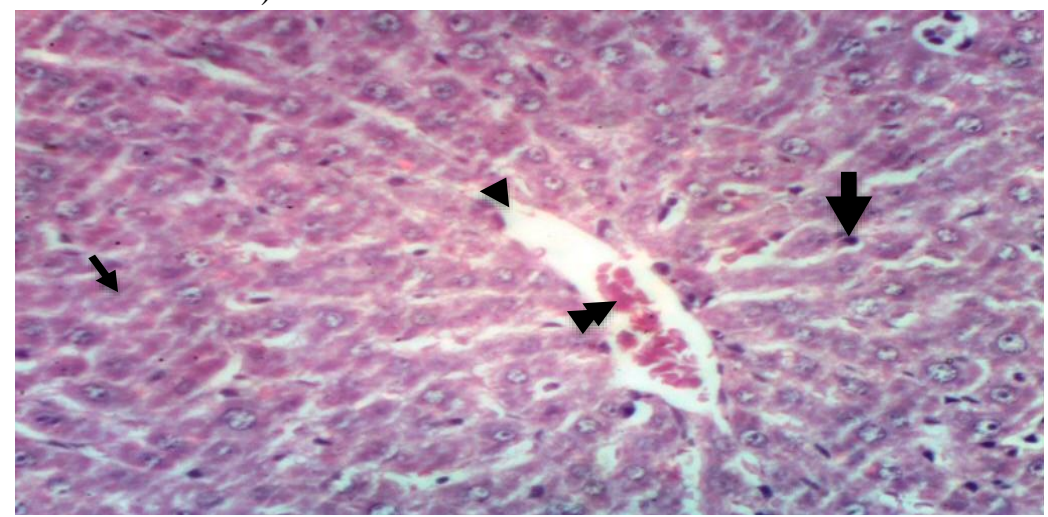

Fig. 4. Representative hematoxylin and eosin staining of liver tissues from the rat group that was fed on HFD+2.5\% FSLs shows kupffer cell activation (thick arrow), and karyolysis of many nuclei (thin arrow), as well as both elongation (arrowhead) and congestion (double arrowhead) of blood vessels (H and E $\times 400$ ). 


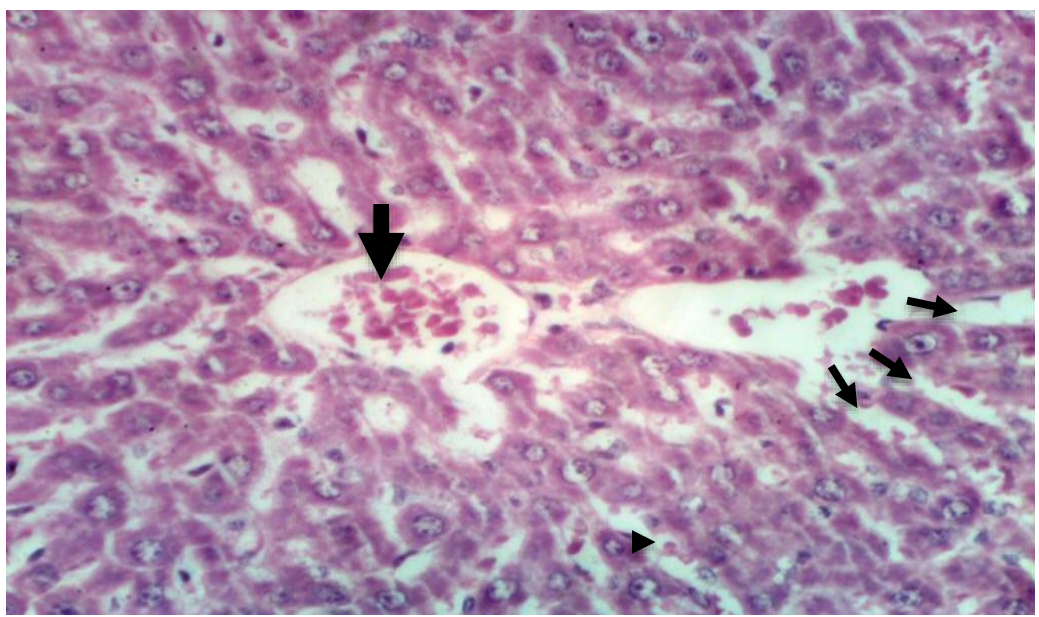

Fig. 5. Representative hematoxylin and eosin staining of liver tissues from the rat group that was fed on HFD $+5 \%$ FSLs shows both congestion (thick arrow) and disruption of blood vessels (thin arrows) as well as dilatation of sinusoids (arrowhead; $\mathrm{H}$ and $\mathrm{E} \times 400$ ).

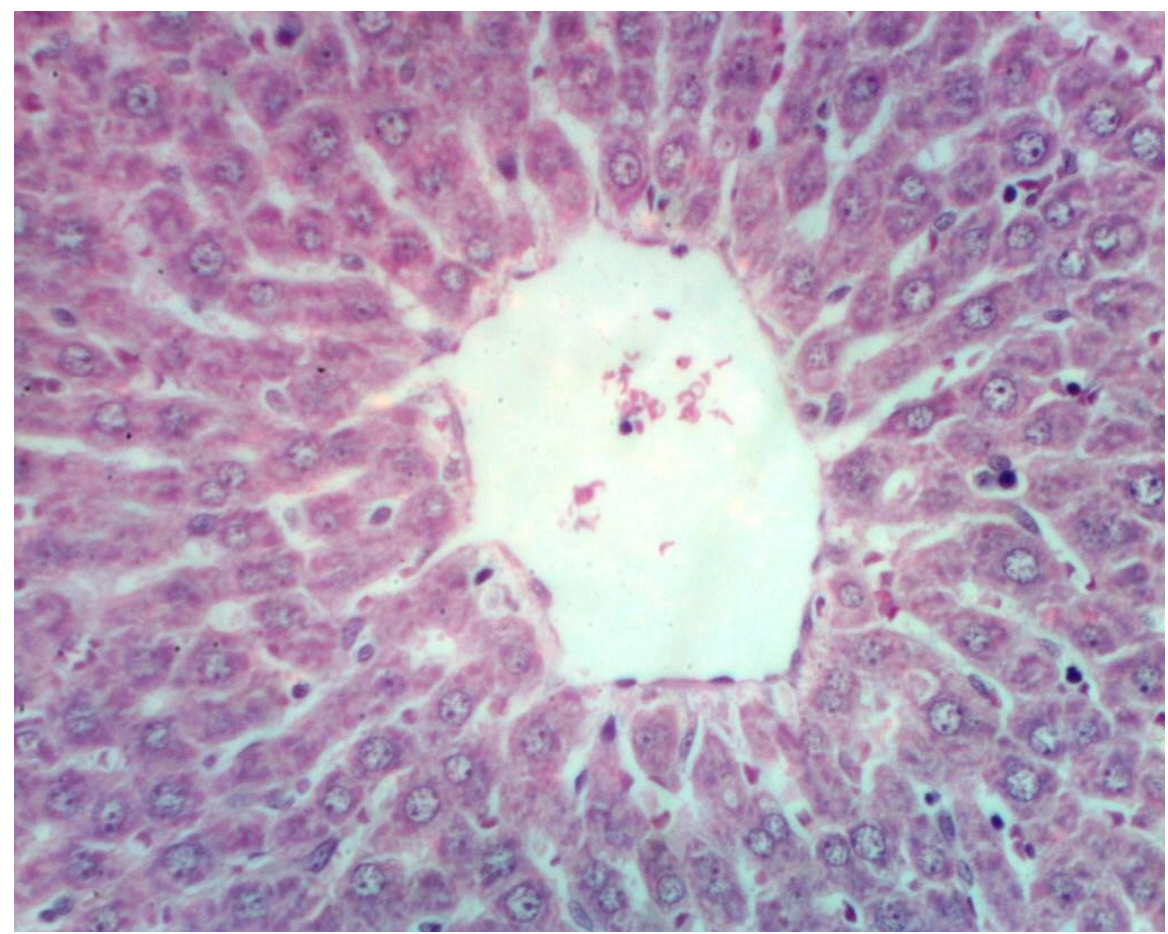

Fig. 6. Representative hematoxylin and eosin staining of liver tissues from the rat group that was fed on $\mathrm{HFD}+7.5 \%$ FSLs shows normal-like arichitecture of hepatocyte around the centeral vein $(\mathrm{H}$ and $\mathrm{E} \times 400)$.

\section{Conclusion}

According to the current findings, it could be concluded that Ficus sycomorus L. leaves can hinder HFD- induced weight gain and prevent its related disorders. So, dietary supplementation with Ficus sycomorus L. leaves is recommended to be implicated in the antiobesity strategies.

\section{References}

[1] B. Drew, A. Dixon, and J. Dixon, Obesity management: update on orlistat, Vasc. Health Risk Manag., 3(6), $2007,817-821$.

[2] J. Brug, and D. Crawford, The obesity pandemic. Is it bad or worse?, Eur. J. Public Health, 19, $2009,570-571$.

[3] Egyptian National Nutrition Institute, Final Report on The National Study: Prevalence of Obesity in Egypt, 2004, pp:22-23.

[4] A.L. de la Garza, F.I. Milagro, N. Boque, J. Campion, and J.A. Martinez, Natural inhibitors of pancreatic lipase as new players in obesity treatment, Planta Med., 77(8), 2011, 773-785.

[5] S.M. Grundy, Multifactorial causation of obesity: implications for prevention, Am. J. Clin. Nutr., 67(3), 1998, 563S-572S.

[6] M.M. El-Sayed, M.A. Mahmoud, H.A. El-Nahas, S.A. El-Toumy, E.A. Eman, and M.A. Ghareeb, Bio-guided isolation and structure elucidation of antioxidant compounds from the leaves of Ficus sycomorus, Pharmacol. online, 3, 2010, 317-332.

[7] T.M. Sarg, F.A. Abbas, Z.I. El-Sayed, and A.M. Mustafa, Two new polyphenolic compounds from Ficus retusa L."variegata" and the biological activity of the different plant extracts, J. Pharmacognosy Phytotherapy 3(7), 2011, 89-100. 
[8] O.A. Adoum, B.O. Micheal, and I.S. Mohammad, Phytochemicals and hypoglycaemic effect of methanol stem-bark extract of Ficus sycomorus Linn (Moraceae) on alloxan induced diabetic Wistar albino rats, Afr. J. Biotechnol., 11(17), 2012, 4095-4097.

[9] N.A. Igbokwe, I.O. Igbokwe, and U.K. Sandabe, Effect of prolonged oral administration of aqueous Ficus sycomorus stem-bark extract on testicular size of growing albino rat, Inter. J. Morphol., 28(4), 2010, 1315-1322.

[10] G.L. Adeshina, C.E. Okeke, N.O. Osugwu, and J.O. Ethinmidu, Preliminary in-vitro antibacterial activities of ethanolic extracts of F. sycomorus and F. platyphylla Del. (Moraceae), Afr. J. Microbiol. Res., 4(8), 2010, 598-601.

[11] M.A. Auda, Medicinal plant diversity in the flora of Gaza Valley, Gaza Strip, Palestine, An -Najah University J. Res. (N. Sc.), 26, 2012, 61-84.

[12] I.I. Nkafamiya, S.A. Osemeahon, U.U. Modibbo, and A. Aminu, Nutritional status of non-conventional leafy vegetables, Ficus asperifolia and Ficus sycomorus, Afr. J. Food Sci., 4(3), 2010, 104-108.

[13] A.U. Osagie, and A.A. Offiong, Nutritional quality of plant foods (Ambik Press, Benin City, Edo State Nigeria, 1998) 131-221.

[14] E.A. Abu-Mustafa, B.A.H. El-Tawil, and M.B.E. Fayez, Constituents of local plants-IV.: Ficus carica L., F. sycomorus L. and F. salicifolia L. leaves, Phytochemist., 3(6), 1963, 701-703.

[15] P.G. Reeves, F.H. Nielsen, and G.C. Fahey, AIN-93 purified diets for laboratory rodents: Final report of the American Institute of Nutrition Ad Hoc Writing Committee on the Reformulation of the AIN-76A Rodent Diet, J. Nutr., 123(11), 1993, 1939-1951.

[16] S.C. Woods, R.J. Seeley, P.A. Rushing, D. D’Alessio, and P. Tso, A controlled high-fat diet induces an obese syndrome in rats, $J$. Nutr., 133(4), 2003, 1081-1087.

[17] L. Angervall, and E. Carlström, Theoretical criteria for the use of relative organ weights and similar ratios in biology, J. Theoretical. Biol., 4(3), 1963, 254-259.

[18] S.C. Liefers, R.F. Veerkamp, M.F.W. te Pas, C. Delavaud, Y. Chilliard, and T. van der Lende, Leptin concentrations in relation to energy balance, milk yield, intake, live weight and estrus in dairy cows, J. Dairy Sci., 86(3), 2003, 799-807.

[19] K. Lorentz, Lipase, in L. Thomas (Ed.), Clinical laboratory diagnostics, $1^{\text {st }}$ ed., (Frankfurt: TH-Books Verlagsgesellschaft, 1998) 95-97.

[20] P. Trinder, Determination of blood glucose using 4- aminophenazone, J. Clin. Path., 22, 1959, 246.

[21] N.J. Jacobs, and P.J. VanDenmark, Enzymatic colorimetric determination of triglycerides, Arch. Biochem. Biophys., 88, 1960, 250255.

[22] N. Richmond, Enzymatic colorimetric test for cholesterol determination, Clin. Chem., 19, 1973, 1350-1356.

[23] W.T. Friedwald, R.L. Levy, and D.S. Fredrickson, Estimation of the concentration of low density lipoprotein cholesterol in plasma without use of the preparative ultracentrifuge, Clin. Chem., 18(6), 1972, 499-502.

[24] S. Reitman, and S. Frankel, A colorimetric method for the determination of serum glutamic pyruvic trnasaminase, J. Clin. Pathol., 28(1), 1957, 56-63.

[25] P.R. Kind, and E.J. King, Estimation of plasma phosphatase by determination of hydrolysed phenol with aminoantipyrine, J. Clin. Path., 7(4), 1954, 322-326.

[26] C.J. Patton, and S.R. Crouch, Enzymatic colorimetric method for determination of urea in serum, Anal. Chem., 49, 1977, 464-469.

[27] H. Bartels, and M. Bohmer, Micro-determination of creatinine, Clin. Chem. Acta., 32(1), 1971, 81-85.

[28] R.A.B. Drury, and E.A. Wallington, Carlton's histological techniques (Oxford University Press, London, New York, Toronto, 1980) $5^{\text {th }}$ ed., 344-345.

[29] G. Sendcor, and W. Cochran, Statistical methods (Lowa State Collage, USA, 1979) $6^{\text {th }}$ ed., 841.

[30] M.E. Lean, and W.P. James, Metabolic effects of isoenergetic nutrient exchange over 24 -hours in relation to obesity in women, Int. J. Obes., 12(1), 1988, 15-27.

[31] T.J. Horton, H. Drougas, A. Brachey, G.W. Reed, J.C. Peters, and J.O. Hill, Fat and carbohydrate overfeeding in humans: different effects on energy storage, Am. J. Clin. Nutr., 62(1), 1995, 19-29.

[32] J.L. Halaas, K.S. Gajiwala, M. Maffei, S.L. Cohen, B.T. Chait, D. Rabinowitz, R.L. Lallone, S.K. Burley, and J.M. Friedman, Weight-reducing effects of the plasma protein encoded by the obese gene, Science, 269(5223), 1995, 543-546.

[33] C.T. Montague, I.S. Farooqi, J.P. Whitehead, M.A. Soos, H. Rau, N.J. Wareham, C.P. Sewter, J.E. Digby, S.N. Mohammed, J.A. Hurst, C.H. Cheetham, A.R. Earley, A.H. Barnett, J.B. Prins, and S. O'Rahilly, Congenital leptin deficiency is associated with severe early-onset obesity in humans, Nature, 387(6636), 1997, 903-908.

[34] A.M. Zivkovic, J.B. German, and A.J. Sanyal, Comparative review of diets for the metabolic syndrome: implications for nonalcoholic fatty liver disease, Am. J. Clin. Nutr., 86(2), 2007, 285-300.

[35] L.I. Gidez, Effect of dietary fat on pancreatic lipase levels in the rat, J. Lipid Res., 14(2), 1973, 169-177.

[36] W.E. Hansen, Effect of dietary fiber on pancreatic lipase activity in vitro, Pancreas, 2(2), 1987, 195-198.

[37] M.R. Dukehart, S.K. Dutta, and J. Vaeth, Dietary fiber supplementation: Effect on exocrine pancreatic secretion in man, Am. J. Clin. Nutr., 50(5), 1989, 1023-1028.

[38] O.O. Olaokun, L.J. McGaw, J.N. Eloff, and V. Naidoo, Evaluation of the inhibition of carbohydrate hydrolysing enzymes, antioxidant activity and polyphenolic content of extracts of ten African Ficus species (Moraceae) used traditionally to treat diabetes, BMC Complement. Altern. Med., 13, 2013, 94.

[39] M. Meydani, and S.T. Hasan, Dietary polyphenols and obesity, Nutrients, 2(7), 2010, 737-751.

[40] R.V. Considine, M.K. Sinha, M.L. Heiman, A. Kriauciunas, T.W. Stephens, M.R. Nyce, J.P. Ohannesian, C.C. Marco, L.J. McKee, L. Thomas, T.L. Bauer, and J.F. Caro, Serum immunoreactive-leptin concentrations in normal-weight and obese humans, N. Engl. J. Med., 334(5), 1996, 292-295.

[41] K. Murakami, S. Sasaki, Y. Takahashi, K. Uenishi, M. Yamasaki, H. Hayabuchi, T. Goda, J. Oka, K. Baba, K. Ohki, R. Watanabe, and Y. Sugiyama, Nutrient and food intake in relation to serum leptin concentration among young Japanese women, Nutr., 23(6), 2007, 461-468.

[42] Y. Nakamura, H. Ueshima, N. Okuda, K. Miura, Y. Kita, T. Okamura, T.C. Turin, A. Okayama, B. Rodriguez, J.D. Curb, and J. Stamler, Relation of dietary and lifestyle traits to difference in serum leptin of Japanese in Japan and Hawaii: The INTERLIPID Study, Nutr. Metab. Tardiovas. $\quad$ Dis., $22(1), \quad 2012, \quad$ 14-22. [43] A.D. Liese, M. Schulz, F. Fang, T.M.S. Wolever, R.B. D’Agostino, K.C. Sparks, and E.J. Mayer-Davis, Dietary glycemic index and glycemic load, carbohydrate and fiber intake, and measures of insulin sensitivity, secretion, and adiposity in the insulin resistance atherosclerosis study, Diabetes Care, 28(12), 2005, 2832-2838.

[44] P. Chowdhury, M. Nishikawa, G.W. Blevins, and P.L. Rayford, Response of rat exocrine pancreas to high-fat and highcarbohydrate diets, Exp. Biol. Med. (Maywood), 223(3), 2000, 310-315.

[45] M.S. Winzell, and B. Ahrén, The high-fat diet-fed mouse: A model for studying mechanisms and treatment of impaired glucose tolerance and type 2 diabetes, Diabetes, 53(suppl. 3), 2004, S215-S219. 
[46] Y. Arita, S. Kihara, N. Ouchi, M. Takahashi, K. Maeda, J. Miyagawa, K. Hotta, I. Shimomura, T. Nakamura, K. Miyaoka, H. Kuriyama, M. Nishida, S. Yamashita, K. Okubo, K. Matsubara, M. Muraguchi, Y. Ohmoto, T. Funahashi, and Y. Matsuzawa, Paradoxical decrease of an adipose-specific protein, adiponectin, in obesity, Biochem. Biophys. Res. Commun., 257(1), 1999, 79-83.

[47] J.P. Whitehead, A.A. Richards, I.J. Hickman, G.A. Macdonald, and J.B. Prins, Adiponectin - a key adipokine in the metabolic syndrome, Diabetes Obes. Metab., 8, 2006, 264-280.

[48] O.J. Pykalisto, P.H. Smith, and J.D. Brunzell, Determinants of human adipose tissue lipoprotein lipase: Effect of diabetes and obesity on basal and diet-induced activity, J. Clin. Invest., 56(5), 1975, 1108-1117.

[49] P. Arner, Differences in lipolysis between human subcutaneous and omental adipose tissues, Ann. Med., 27(4), 1995, 435-438.

[50] G.F. Lewis, and G. Steiner, Acute effects of insulin in the control of VLDL production in humans: Implications for the insulinresistant state, Diabetes Care, 19(4), 1996, 390-393.

[51] R.A. DeFronzo, and E. Ferrannini, Insulin resistance: A multifaceted syndrome responsible for NIDDM, obesity, hypertension, dyslipidemia, and atherosclerotic cardiovascular disease, Diabetes Care, 14(3), 1991, 173-194.

[52] J.R. Patsch, G. Miesenbock, T. Hopferwieser, V. Muhlberger, E. Knapp, J.K. Dunn, A.M. Gotto Jr, and W. Patsch, Relation of triglyceride metabolism and coronary artery disease: Studies in the postprandial state, Arterioscler. Thromb., 12(11), 1992, 13361345 .

[53] V.T. Samuel, Z.X. Liu, X. Qu, B.D. Elder, S. Bilz, D. Befroy, A.J. Romanelli, and G.I. Shulman, Mechanism of hepatic insulin resistance in non-alcoholic fatty liver disease, J. Biol. Chem., 279(31), 2004, 32345-32353.

[54] J. Westerbacka, K. Lammi, A.M. Hakkinen, A. Rissanen, I. Salminen, A. Aro, and H. Yki-Jarvinen, Dietary fat content modifies liver fat in overweight nondiabetic subjects, J. Clin. Endocrinol. Metab., 90(5), 2005, 2804-2809.

[55] K. Mehta, D.H. Van Thiel, N. Shah, and S. Mobarhan, Nonalcoholic fatty liver disease: Pathogenesis and the role of antioxidants, Nutr. Rev., 60(9), 2002, 289-293.

[56] E.S. Abdel-Hameed, Total phenolic contents and free radical scavenging activity of certain Egyptian Ficus species leaf samples, Food Chem., 114(4), 2009, 1271-1277.

[57] N. Deji, S. Kume, S. Araki, M. Soumura, T. Sugimoto, K. Isshiki, M. Chin-Kanasaki, M. Sakaguchi, D. Koya, M. Haneda, A. Kashiwagi, and T. Uzu, Structural and functional changes in the kidneys of high-fat diet-induced obese mice, Am. J. Physiol. Renal Physiol., 296(1), 2009, F118-F126.

[58] S. Kobayashi, K. Maesato, H. Moriya, T. Ohtake, and T. Ikeda, Insulin resistance in patients with chronic kidney disease, Am. J. Kidney Dis., 45(2), 2005, 275-280. 